\title{
Establishing a Cochlear Implant Program in a Rural Area of Germany with Special Respect to Older Patients
}

\author{
Peter Rolf Issing*, Anja Michler \\ Department of Otorhinolaryngology, Head, Neck \& Plastic Facial Surgery, Klinikum Bad Hersfeld GmbH, Bad Hersfeld, Germany \\ Email: * peter.issing@klinikum-hef.de
}

How to cite this paper: Issing, P.R. and Michler, A. (2018) Establishing a Cochlear Implant Program in a Rural Area of Germany with Special Respect to Older Patients. International Journal of Otolaryngology and Head \& Neck Surgery, 7, 35-42. https://doi.org/10.4236/ijohns.2018.72005

Received: December 16, 2017

Accepted: March 6, 2018

Published: March 9, 2018

Copyright (c) 2018 by authors and Scientific Research Publishing Inc. This work is licensed under the Creative Commons Attribution International License (CC BY 4.0).

http://creativecommons.org/licenses/by/4.0/

\begin{abstract}
Objective: The present study aimed to demonstrate the patient outcomes after cochlear implantation in a rural area of Germany with special respect to older patients. Study Design: Retrospective Study. Setting: ENT-Department of Bad Hersfeld as an academic teaching hospital of the Justus-Liebig-University of Giessen. This is located in a rural county in Germany. Patients: A consecutive series of 217 patients implanted between 2003 and 2017. Intervention: Patients were implanted with different cochlear implant devices by the same surgeon in a standard procedure. In cases of chronic otitis media a middle ear obliteration was performed 6 months prior to cochlear implantation. Main Outcome Measures: Patients were divided in two groups: group 1 was 18 to 65 years of age and group 2 was older than 65 years. Pre- and postoperative hearing and speech understanding evaluated by the Freiburg monosyllable word test and the HSM-sentence test in the group of patients. Results: The mean preoperative speech understanding of group 1 was $0.5 \%$ for monosyllables at $60 \mathrm{~dB}$ and $2.7 \%$ at $80 \mathrm{~dB}$. Group 2 showed similar results with $0.2 \%$ and $1.2 \%$. In the HSM-test, group 1 had a speech understanding of $2.6 \%$ and group 2 of $3.2 \%$. No statistically significant difference could be found between both groups. After cochlear implantation mean speech understanding at 60 $\mathrm{dB}$ increased in group 1 to $53.2 \%$ and $65.1 \%$ at $80 \mathrm{~dB}$ respectively. Group 2 had an improvement to $51.8 \%$ at $60 \mathrm{~dB}$ and $68.3 \%$ and $80 \mathrm{~dB}$. The results in the HSM-sentence test were $77.8 \%$ in group 1 and $83.7 \%$ in group $2(\mathrm{p}=$ 0.47 ). Both groups had a significant increase in speech understanding concerning both tests after cochlear implantation $(\mathrm{p}=0.0001)$ whereas we could not confirm any significant difference between the younger and older CI-recipients in the monosyllable word test. During the observation period no major complications had to be observed. Conclusion: Our data suggest that cochlear implantation in a rural area of Germany is feasible without increased
\end{abstract}


risk and provides good hearing results even in older patients.

\section{Keywords}

Cochlear Implantation, Rural Area, Older Patients

\section{Introduction}

The cochlear implant (CI) is an established method of hearing rehabilitation in pre- and postlingual deafness in appropriate candidates. However, the procedures of patient selection, surgery and especially postoperative fitting of the speech processor require an interdisciplinary team. Therefore, cochlear implant programs were initially founded at selected university centers in the past. In the meantime, cochlear implantation has reached more and more the status of a routine operation that makes it suitable for non academic hospitals subject to the above mentioned conditions.

Furthermore, the demographic change is a challenge for industrial nations such as Germany. The increasing number of older people with a significant multimorbidity faces a health system which tends to focus on a few centers offering services like cochlear implantation. This means a serious problem in rural areas with limited infrastructure to guarantee access for this often physically and mentally handicapped group. Based on these considerations, we tried to demonstrate the feasibility of a cochlear implant program at a non-university hospital in a rural area of Germany with special respect to older patients. The first author has undergone his professional training at a large university clinic and performed more than 700 cochlear implantations so far.

Bad Hersfeld is a district town in the federal state of Hessen and has about 29,000 inhabitants; this number is decreasing for the last years. The rural district of Hersfeld-Rotenburg is located quite in the middle of Germany where 121.000 people are living. One of the main products is wood due to the large forests surrounding this town. The distance to larger metropolitan centers such as Würzburg in the south, Göttingen in the north, Frankfurt in the west and Erfurt in the east with traditionally established cochlear implant programs averages out of $130 \mathrm{ki}-$ lometers.

\section{Material and Methods}

A total number of 217 adult subjects implanted between 2003 and 2017 by the first author was included in this retrospective study. The hearing results of the patients older than 65 years of age were of special interest. These results were compared with those of the patients aged younger than 65 years.

The demographical data are presented in Figure 1. Usually the patients chose the type of cochlear implant devices out of three established companies (Advanced Bionics, Cochlear, MEDEL) after a thorough medical and technical 


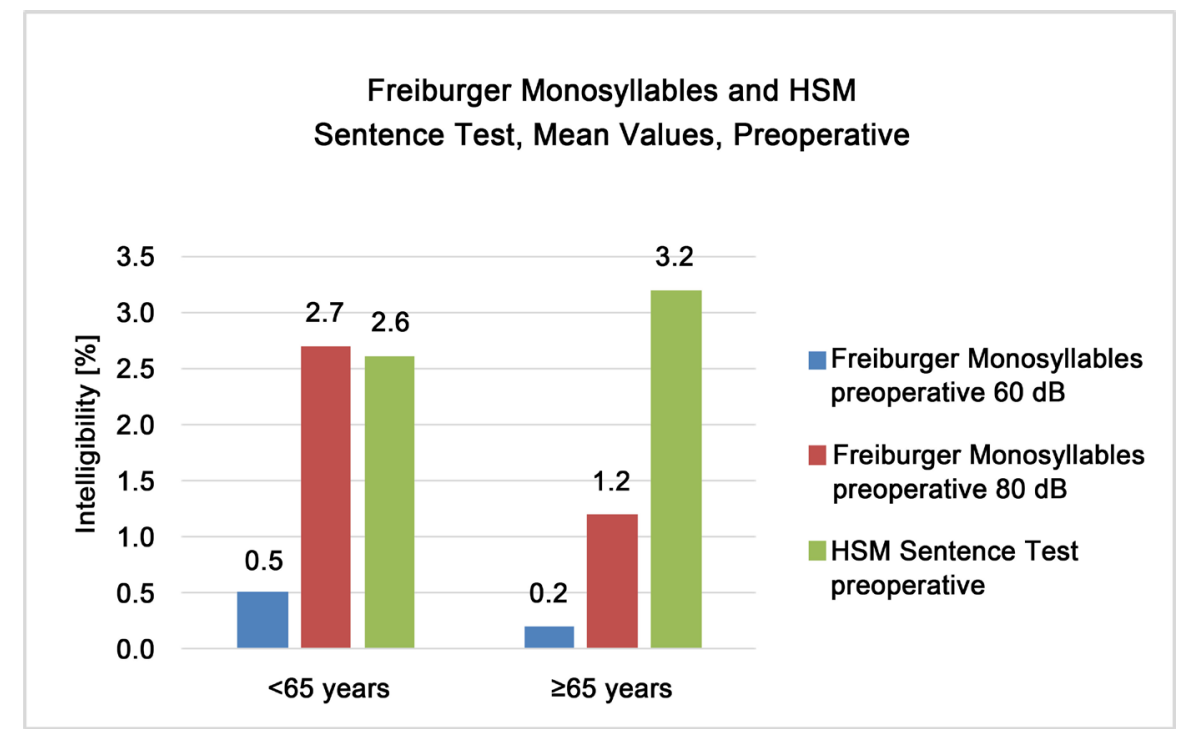

Figure 1. Speech intelligibility of monosyllables in the Freiburger test at 60 and $80 \mathrm{~dB}$ and the HSM test at $70 \mathrm{~dB}$ for the patients younger and older than 65 years before implantation.

information if there were no specific medical reasons which made this procedure not appropriate.

For analysis, the demographic variables were expressed as means and range using Microsoft Excel (Microsoft Corporation, Redmond, WA, USA), (2010). The statistical evaluation was carried out by using ANOVA (IBM SPSS Statistics, version 23, IBM, Chicago, IL). Statistical significance was defined as $p<0.05$ in Chi-Square-Test.

\subsection{Preoperative Evaluation}

All patients underwent a standardized preoperative evaluation with clinical examination, audiometric testing, technical advice, consulting and imaging (HR-CT and MRI).

Audiological Testing.

Pure tone audiometry.

Stapedial reflex.

TEOAE/DPOAE.

Speech audiometry:

- Freiburger Numbers and Monosyllables.

- HSM-Sentence-Test.

Brainstem Audiometry.

Caloric Testing.

c/oVEMP.

\subsection{Surgical Procedure}

All surgeries were performed in a standardized procedure in general anesthesia with facial nerve monitoring (NIM 3.0, Medtronic, Minnesota). 
In cases of a coincident chronic otitis media or after canal wall down surgery the external auditory meatus was closed and the middle ear cleft was obliterated with abdominal wall fat prior to cochlear implantation which was performed during a second surgery after 6 months $(n=12)$. This technique was previously described in detail elsewhere [1]. After electrode insertion the impedances were measured and the electrically stapedius reflex was evoked as well as the E-CAP to confirm device integrity and electrode-nerve-interface functionality.

\subsection{Postoperative Setting}

The first fitting of the speech processor was scheduled about 4 weeks following implantation. There is quite a variety concerning the procedure of the rehabilitation period due to different patients' preference. About two thirds of the patient selected a fitting on an outpatient basis in our department with a weekly schedule of follow-ups. The others took part in an inpatient procedure in special rehabilitation centers such as Bad Nauheim which lasts three weeks in average. After stabilization of the map patients presented at least once a year for medical and audiological control.

Audiometric testing consisted of free field speech audiometry as mentioned above. The audiological follow up of all patients in this study was at least 6 months after cochlear implantation; however, some patients are using their implants for years.

\section{Results}

A total number of 217 adult patients was included in this study. The average age was 62.7 years with a maximum of 88 years. The sex ratio was 102 males and 115 females (Table 1). Unilateral implantation was performed in 187 cases, whereas 50 patients were provided with a bilateral CI.

The study focuses on the comparison of the 217 adult patients who were divided into two groups:

Table 1. Distribution of age and gender.

\begin{tabular}{ccccccc}
\hline $\begin{array}{c}\text { Age at time } \\
\text { of surgery }\end{array}$ & $\begin{array}{c}\text { Number } \\
\text { of patients }\end{array}$ & Males & Females & Percentage & $\begin{array}{c}\text { Percentage } \\
\text { Males }\end{array}$ & $\begin{array}{c}\text { Percentage } \\
\text { Females }\end{array}$ \\
\hline $17-25$ & 8 & 3 & 5 & 3.7 & 1.4 & 2.3 \\
$26-35$ & 14 & 4 & 10 & 6.5 & 1.8 & 4.6 \\
$36-45$ & 18 & 9 & 9 & 8.2 & 4.1 & 4.1 \\
$46-55$ & 31 & 12 & 19 & 14.3 & 5.5 & 8.8 \\
$56-65$ & 47 & 25 & 22 & 21.7 & 11.5 & 10.1 \\
$66-75$ & 65 & 34 & 31 & 30 & 15.7 & 14.3 \\
$76-85$ & 32 & 14 & 18 & 14.7 & 6.5 & 8.3 \\
$86-95$ & 2 & 1 & 1 & 0.9 & 0.5 & 0.5 \\
$96-100$ & 0 & 0 & 0 & 0 & 0 & 0 \\
Total & 217 & 102 & 115 & 100 & 47 & 53 \\
\hline
\end{tabular}


Group one consists of persons younger than 65 years $(\mathrm{n}=118)$ and group two of persons older than 65 years $(n=99)$. The oldest participant is a lady who was implanted at the age of 88 years. She is 95 years old now and is one of our best performers with a speech understanding of $95 \%$ monosyllables at $60 \mathrm{~dB}$. No patient was excluded from cochlear implant surgery due to anaesthesiological reasons.

Preoperative speech understanding in group 1 was $0.5 \%$ and $2.7 \%$ monosyllables at 60 resp. $80 \mathrm{~dB}$. Group 2 demonstrated similar results with $0.2 \%$ and $1.2 \%$. Considering the HSM-test the group of the young patients reached a score of $2.6 \%$ and the older patient group 3.2\%. Real-ear unaided gain (REUG) was used in both tests as a relevant number of the patients did not use their hearing aids any longer prior surgery (Figure 1). All in all no statistically significant differences could be found between the both groups prior surgery (Figure 1).

After implantation group 1 showed a speech understanding of $53.2 \%$ monosyllables at $60 \mathrm{~dB}$ and group $265.1 \%(\mathrm{p}=0.132)$.

At $80 \mathrm{~dB}$ group 1 had a speech understanding of $65.1 \%$ and the older patients managed to understand $68.3 \%(\mathrm{p}=0.452)$.

Considering the HSM-sentence-test group 1 reached $77.8 \%$ and group two $83.7 \%(\mathrm{p}=0.47)$.

These data demonstrate that the older group of patients reached equivalent hearing results. In the HSM-Test their speech understanding even is slightly better.

Unsurprisingly the hearing results before and after cochlear implantation demonstrate a highly significant improvement in both groups concerning all tests used in this study $(\mathrm{p}=0.0001)$.

The postoperative results are summarized in Figure 2.

As side effects we observed vertigo in 8 patients with rotary vertigo in 3 and postural vertigo in 5 cases. Initially, the intensity of vertigo was high in two individuals, however, these problems improved over time.

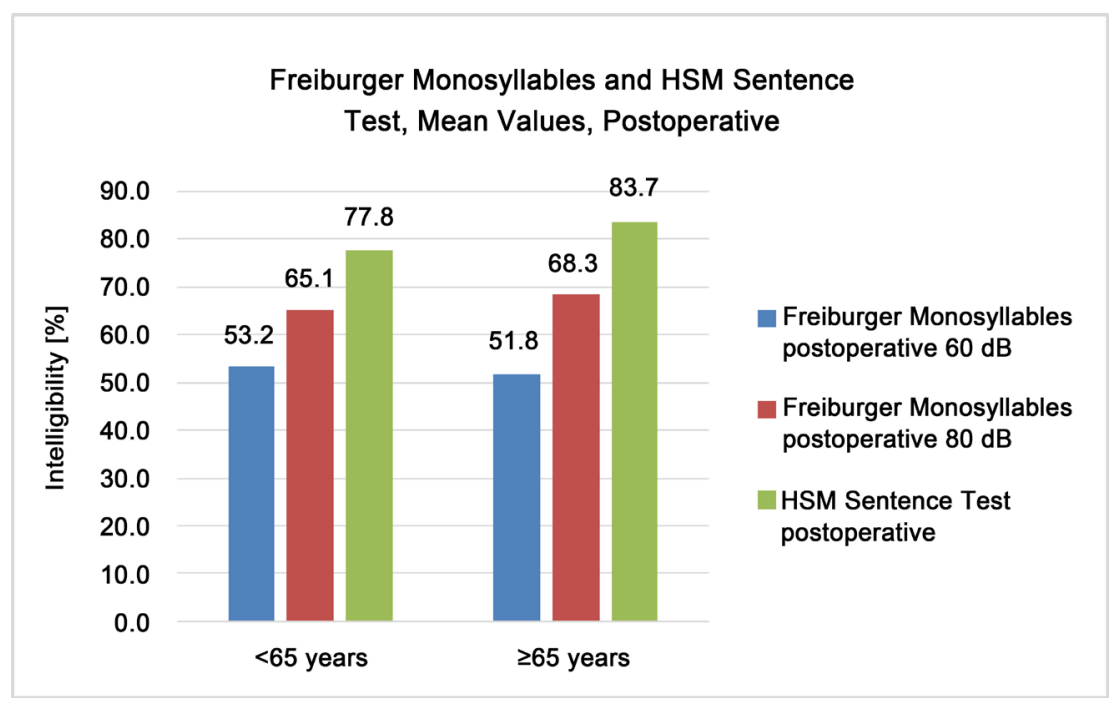

Figure 2. Speech intelligibility of monosyllables in the Freiburger test at 60 and $80 \mathrm{~dB}$ and the HSM test at $70 \mathrm{~dB}$ for the patients younger and older than 65 years after implantation. 
Dysgeusia was noticed in 3 patients and was not measured separately. In one female patient an irritating dysgeusia persisted with a soap like taste which meant an impairment of the patient's quality of life.

Reimplantation was necessary in 9 individuals. The reasons were:

- an impact to the CI with a subsequent soft failure which could not be proved preoperatively $(n=2)$.

- device failure of the Nucleus 512 implant $(n=4)$.

- stimulation of the facial nerve by a straight electrode which was changed to a modiolus hugging type $(\mathrm{n}=1)$.

- 2 patients wished to have removed their implants due to unsatisfying hearing; in both cases there was an obliteration of the cochlea with subsequent incomplete electrode insertion.

We did not observe any major complications such as facial palsy, flap break down or wound infection. There were no perioperative age related complications (heart failure, stroke, thromboembolism etc.) found. The follow up was at least 6 months.

\section{Discussion}

There is increasing evidence that cochlear implantation is beneficial for old and even very old patients [2]-[7]. Cognitive function can also improve after hearing restoration with better speech understanding. Moreover, it has a positive influence on social activity as well as on quality of life [5].

Considering the development in industrial countries where population is getting older and with all the outgrowths of age related comorbidities on the one hand. On the other hand, especially younger people tend to move to large cities with the consequence that old inhabitants stay at the rural areas where the infrastructure and medical resources deteriorate. Hence, older patients in rural areas might have difficulties to get access to modern and complex medical care. This has been proved by Hixon et al. and Bush et al. for the United States of America [8] [9] [10], although the geographical conditions are different in Germany.

To the best of our knowledge our investigation is the first study to evaluate results of hearing rehabilitation by cochlear implantation with a special focus on the elderly in a rural area of Germany. Comparing the younger and older CI-recipients there is no real difference in speech understanding which has also been confirmed by several studies [2] [3] [7] [11]. Nevertheless, the older patients show a benefit from cochlear implantation. Interestingly, the older group demonstrates a statistically significant better understanding in the HSM-sentence test which could be a hint for a higher skill in language combination whereas the results in monosyllable detection is only by trend more favorable in this group of patients. As these results do not show large differences we do not want to overinterpret these observations due to the small sample size.

In our study we could not find a higher medical risk of the surgical procedure for the old patients. All of the patients showed an improved hearing situation af- 
ter CI surgery. Provided that a careful anesthesiological check takes place prior implantation there is no reason not to offer this reconstructive operation to very old people if the implanting center has the surgical and pedagogical expertise [12] [13] [14]. In case of severe comorbidity local anesthesia might be an alternative to provide critically ill candidates with an implant [15].

Our hearing results are comparable to the data of large university centers as mentioned by Huhnd [16] and Eidam [17]. Although the group at the Charité in Berlin used the level of $70 \mathrm{~dB}$ for testing the intelligibility of the monosyllables, their 55 patients reached an understanding of $58.2 \%$ after implantation [16]. The Freiburg cochlear implant center describes similar methods of testing compared to our procedures and reports a speech understanding of $57.0 \%$ monosyllables at a level of $60 \mathrm{~dB}$ [17]. In our department the younger group understood 53.2\% monosyllables at $60 \mathrm{~dB}$ and the older patients $51.8 \%$. It is important to emphasize that our patients are not selected and not only the good performers' results are presented.

\section{Conclusion}

Our results demonstrate that cochlear implantation can successfully and safely be realized in a rural setting if several prerequisites are fulfilled. Especially older patients who otherwise would have difficulties to get access to this effective method of hearing rehabilitation in limited centers benefit from this procedure [8] [9] [10].

\section{Acknowledgements}

The authors acknowledge Dr. Ralf Degenhardt for the statistical analysis.

\section{References}

[1] Issing, P.R., Schönermark, M.P., Kempf, H.G., Ernst A. and Lenarz, T. (1998) Cochlear Implantation in Patients with Chronic Otitis: Indications for Subtotal Petrosectomy and Obliteration of the Middle Ear. Skull Base Surgery, 8, 127-131. https://doi.org/10.1055/s-2008-1058571

[2] Chiba, H., Hagiwara, A., Schimizu, A., et al. (2002) The Results of Cochlear Implantation in the Elderly. In: Kubo, T., Takahashi, Y. and Iwaki, T., Eds., Cochlear Implants-An Update, Kugler Publications, The Hague, 469-478.

[3] Hast, A., Schlücker, L., Digeser, F., Liebscher, T. and Hoppe, U. (2015) Speech Perception of Elderly Cochlear Implant Users under Different Noise Conditions. Otology \& Neurotology, 36, 1638-1643. https://doi.org/10.1097/MAO.0000000000000883

[4] Herzog, M., Schön, F., Müller, J., et al. (2013) Long Term Results after Cochlear Implantation in Elderly Patients [in German]. Laryngo-Rhino-Otologie, 82, 490493.

[5] Mosnier, I. (2012) Cochlear Implant Outcomes in the Elderly. Audiology and Neurotology, 17, 20-22.

[6] Skarzynski, P.H., Oszewski, L., Skarzynski, H., et al. (2012) Cochlear Implantation in the Aging Population. Audiology and Neurotology, 17, 15-17. 
[7] Wong, D.J.Y., Moran, M. and O’Leary, S.J. (2015) Outcomes after Cochlear Implantation in the Very Elderly. Otology \& Neurotology, 37, 46-51. https://doi.org/10.1097/MAO.0000000000000920

[8] Hixon, B., Chan, S., Adkins, M., Shinn, J.B. and Bush, M.L. (2016) Timing and Impact of Hearing Healthcare in Adult Cochlear Implant Recipients: A Rural-Urban Comparison. Otology \& Neurotology, 37, 1320-1324. https://doi.org/10.1097/MAO.0000000000001197

[9] Bush, M.L., Burton, M., Loan, A., et al. (2013) Timing Discrepancies of Early Intervention Hearing Services in Urban and Rural Cochlear Implant Recipients. Otology \& Neurotology, 34, 1630-1635. https://doi.org/10.1097/MAO.0b013e31829e83ad

[10] Bush, M.L., Hardin, B., Rayle, C., et al. (2015) Rural Barriers to Early Diagnosis and Treatment of Infant Hearing Loss in Appalachia. Otology \& Neurotology, 36, 93-98.

[11] Zwolan, T.A., Henion, K., Segel, P. and Runge, C. (2014) The Role of Age on Cochlear Implant Performance, Use and Health Utility: A Multicenter Clinical Trial. Otology \& Neurotology, 35, 1560-1568.

https://doi.org/10.1097/MAO.0000000000000583

[12] Athanasiadis-Sismanis, A. (2012) Intracranial Complications of Cochlear Implantation in the Elderly. Audiology and Neurotology, 17, 20.

[13] Büchsenschütz, K., Arnolds, J., Bagus, H., Fahimi, F., Günnicker, M., Lang, S. and Arweiler-Harbeck, D. (2015) Surgical Risk Profile and Audiological Outcome in the Elderly after Cochlea-Implantation. Laryngo-Rhino-Otologie, 94, 670-675. (In German)

[14] Terry, B., Kelt, R.E. and Jeyakumar, A. (2015) Delayed Complications after Cochlear Implantation. JAMA Otolaryngology_Head \& Neck Surgery, 141, 1012-1017. https://doi.org/10.1001/jamaoto.2015.2154

[15] Pateron, B., Bakhos, D., Lelouarn, A., Bordure, P., Bozorg Grayeli, A., Godey, B. and Lescann, E. (2016) Local Anaesthesia and Conscious Sedation for Cochlear Implantation: Experience with 20 Patients. The Journal of Laryngology \& Otology, 130, 151-156. https://doi.org/10.1017/S0022215115003229

[16] Huhnd, L.E. (2011) Einfluss der Cochlea Implantat Versorgung auf Lebensqualität, Sprachverstehen, Tinnitus und psychischer Komorbiditäten unter besonderer Berücksichtigung älterer Menschen. Thesis, Berlin. (In German)

[17] Eidam, T. (2016) Einfluss moderner Sprachprozessoren auf das Rehabilitationsergebnis bei Cochlea Implantat Patienten. Thesis, Freiburg. (In German) 